\title{
Key Approach to Expanding the Less Invasive Off-Pump Coronary Artery Bypass Grafting Procedure Worldwide
}

\author{
Noboru Motomura, MD, $\mathrm{PhD}$
}

$\mathbf{M}$ inimal invasiveness is currently a big topic in cardiac surgery. 1,2 Off-pump coronary artery bypass grafting (OPCAB) is widely accepted as a less invasive technique from the viewpoint of cardiac operative procedure, ${ }^{3}$ but controversy still exists over whether this procedure really is better than the conventional on-pump and/or cardiac arrest procedure. ${ }^{4}$

\section{Article p 2177}

In this issue of the Journal, Ohira et $\mathrm{al}^{5}$ report on the longterm safety and effectiveness of OPCAB, not only in younger patients but also in the elderly population. The distribution of age in their report is similar to that in a previous report using a national database in Japan (JACVSD; Japan Adult Cardiovascular Surgery Database). ${ }^{6}$ Their study group included $34 \%$ Young ( $<65$ years), $42 \%$ Early elderly (65-74 years), and $24 \%$ Late elderly ( $\geq 75$ years). The proportions of sex, diabetes mellitus, and cardiac status were also similar to the nationwide analysis. So their study population reflected the Japanese status in general. In-hospital mortality in their series was $1.0 \%$ overall, which is better than the nationwide report $(1.4 \%){ }^{7}$ This excellent outcome may be attributed in part to procedure intention. The rate of OPCAB in Japan is approximately $60 \%$, which is higher than in North America. In the study authors' institute the ratio of OPCAB to total CABG cases is $81 \%$ (954 of 1,177$)$, which is much higher than the Japanese average. And their case series was operated by only 2 surgeons over the
15 -year study period. The authors explain that OPCAB is technically demanding, not only the anastomosis but also heart positioning, and they suggest that $\mathrm{OPCAB}$ cannot be performed by all surgeons, otherwise the outcome following OPCAB may be unfavorable, as in the ROOBY study. I agree with this in part, but disagree in another part. A good surgical procedure can be done by everybody provided they are trained appropriately. OPCAB should be able to be accomplished by a large number of surgeons following suitable training. OPCAB should not be a special procedure for a limited group of surgeons. Excellent education in OPCAB is the key to its expansion and penetration worldwide.

Several years ago, a multicenter study was done in Japan using the same nationwide database (JACVSD) regarding the effectiveness of OPCAB in comparison with conventional (on-pump beating or arrest) $\mathrm{CABG}$ (ConCAB) on the basis of propensity-matched analysis. ${ }^{8}$ At that time, only 120 hospitals (out of $>600$ hospitals) were involved in the Database and the mortality rate was worse than currently (hospital mortality was $2.1 \% / 3.9 \%$; OPCAB/ConCAB). But the effectiveness was apparent even in that era and some information is summarized in Table.

OPCAB is less invasive for patients, but more stressful and invasive for the surgeons. To overcome this situation, the education system for OPCAB should be prepared more intensively. Then the message from the ROOBY study will become attenuated and patients everywhere in the world will enjoy the benefit of OPCAB.

\begin{tabular}{|c|c|c|c|}
\hline Baseline & Conventional & Off-pump & $P$ value \\
\hline No. & 2,283 & 2,301 & \\
\hline Age/male & 68.2 years $/ 76.9 \%$ & 68.5 years $/ 76.3 \%$ & $0.31 / 0.63$ \\
\hline DM/PAD & 49.2/14.6 (\%) & $48.5 / 15.4(\%)$ & $0.62 / 0.48$ \\
\hline Renal failure & $13.4 \%$ & $14.1 \%$ & 0.49 \\
\hline Morbidity & Conventional (\%) & Off-pump (\%) & Odds ratio $(95 \% \mathrm{Cl})$ \\
\hline Stroke & 2.0 & 1.2 & $0.42(0.38-0.98)$ \\
\hline New dialysis & 4.6 & 2.7 & $0.57(0.41-0.78)$ \\
\hline Any reoperation & 8.4 & 5.8 & $0.67(0.53-0.84)$ \\
\hline ICU stay $>8$ days & 10.0 & 5.3 & $0.49(0.39-0.62)$ \\
\hline
\end{tabular}

$\mathrm{CABG}$, coronary artery bypass grafting; $\mathrm{Cl}$, confidence interval; $\mathrm{DM}$, diabetes mellitus; $\mathrm{PAD}$, peripheral artery disease.

The opinions expressed in this article are not necessarily those of the editors or of the Japanese Circulation Society.

Received August 30, 2015; accepted August 31, 2015; released online September 14, 2015

Department of Cardiovascular Surgery, Sakura Medical Center, Toho University, Chiba, Japan

Mailing address: Noboru Motomura, MD, PhD, Department of Cardiovascular Surgery, Sakura Medical Center, Toho University, 564-1

Shimoshizu, Sakura, Chiba 285-8741, Japan. E-mail: noboru@motomura.org

ISSN-1346-9843 doi:10.1253/circj.CJ-15-0940

All rights are reserved to the Japanese Circulation Society. For permissions, please e-mail: cj@j-circ.or.jp 


\section{References}

1. Hiraoka A, Totsugawa T, Kuinose M, Nakajima K, Chikazawa G, Tamura K, et al. Propensity score-matched analysis of minimally invasive aortic valve replacement. Circ J 2014; 78: 2876-2881.

2. Ishikawa N, Watanabe G, Tomita S, Yamaguchi S, Nishida Y, Iino K. Robot-assisted minimally invasive direct coronary artery bypass grafting: ThoraCAB. Circ J 2014; 78: 399-402.

3. Polomsky M, He X, O'Brien SM, Puskas JD. Outcomes of off-pump versus on-pump coronary artery bypass grafting: Impact of preoperative risk. J Thorac Cardiovasc Surg 2013; 145: 1193-1198.

4. Hattler B, Messenger JC, Shroyer AL, Collins JF, Haugen SJ, Garcia JA, et al; Veterans Affairs Randomized On/Off Bypass Study Group. Off-pump coronary artery bypass surgery is associated with worse arterial and saphenous vein graft patency and less effective revascularization: Results from the Veterans Affairs Randomized On/Off Bypass (ROOBY) trial. Circulation 2012; 125: 2827-2835.

5. Ohira S, Doi K, Numata S, Yamazaki S, Yamamoto T, Fukuishi M, et al. Does age at operation influence the short- and long-term out- comes of off-pump coronary artery bypass grafting? Circ J 2015; 79: $2177-2185$.

6. Saito A, Motomura N, Miyata H, Takamoto S, Kyo S, Ono M. Agespecific risk stratification in 13488 isolated coronary artery bypass grafting procedures. Interact Cardiovasc Thorac Surg 2011; 12: $575-580$.

7. Committee for Scientific Affairs, The Japanese Association for Thoracic Surgery; Masuda M, Kuwano H, Okumura M, Amano J, Arai $\mathrm{H}$, Endo S, et al. Thoracic and cardiovascular surgery in Japan during 2012: Annual report by the japanese association for thoracic surgery. Gen Thorac Cardiovasc Surg 2014; 62: $734-764$ (erratum: 2015; 63: $120-122$ ).

8. Motomura N, Miyata H, Tsukihara H, Takamoto S; JCVSDO. Offpump procedure reduced the risk adjusted mortality of coronary artery bypass surgery by half in comparison with conventional procedure: Propensity score analysis from the Japanese National Database (JACVSD). Interact Cardiovasc Thorac Surg 2010; 10(Suppl 1): $\mathrm{S} 12$. 